\title{
Monoinstitutional real world experience in management of Vinflunine as second line therapy for transitional cell carcinoma of the urothelium
}

\author{
Giovanni Schinzari ${ }^{1}$, Ernesto Rossi ${ }^{1}$, Francesco Pierconti ${ }^{2}$, Giovanna Garufi ${ }^{1}$, Santa \\ Monterisi ${ }^{1}$, Antonia Strippoli ${ }^{1}$, Ettore D'Argento ${ }^{1}$, Alessandra Cassano ${ }^{1}$ and Carlo \\ Barone $^{1}$ \\ ${ }^{1}$ Department of Medical Oncology, Università Cattolica del Sacro Cuore, Rome, Italy \\ ${ }^{2}$ Department of Pathology, Università Cattolica del Sacro Cuore, Rome, Italy \\ Correspondence to: Giovanni Schinzari, email: giovanni.schinzari@unicatt.it
}

Keywords: vinflunine; transitional cell carcinoma of the urothelium; second line; toxicity

Received: July 18, 2017 Accepted: December 03, $2017 \quad$ Published: January 11, 2018

Copyright: Schinzari et al. This is an open-access article distributed under the terms of the Creative Commons Attribution License 3.0 (CC BY 3.0), which permits unrestricted use, distribution, and reproduction in any medium, provided the original author and source are credited.

\section{ABSTRACT}

Vinflunine is the only cytotoxic agent tested as a second line therapy in transitional cell carcinoma of the urothelium in a phase III trial. It is not largely employed in clinical practice because of the high incidence of grade 3-4 toxicity. We evaluated efficacy and safety of Vinflunine at the dose of $280 \mathrm{mg} / \mathrm{m}^{2}$ every 3 weeks associated with primary prophylaxis with granulocyte growth factors and laxatives for patients progressed after platinum + Gemcitabine. Overall survival was $\mathbf{8 . 5}$ months, progression-free survival 4.33 months and response rate $25 \%$, with disease control rate $57.2 \%$. Grade III-IV neutropenia occurred in $10.7 \%$ of the patients, grade IIIIV anemia and grade III thrombocytopenia in $10.7 \%$ and $7.2 \%$, respectively. Among non haematological toxicity, grade I-II constipation was reported in $14.2 \%$ of the patients, without grade III-IV adverse events. No discontinuation for toxicity was observed. This study underlines that Vinfluinine at a dose of $280 \mathrm{mg} / \mathrm{m}^{2}$ associated with primary prophylaxis for neutropenia and constipation is effective and with a favorable toxicity profile.

\section{INTRODUCTION}

Transitional cell carcinomas of the urothelium (TCCU) represent more than $90 \%$ of all cancers of the urinary tract, among which $90 \%$ are localized in the bladder. [1-2]. In Europe bladder cancer is the fifth diagnosed malignancy accounting for $4.7 \%$ of all human neoplasms [3].

Approximately half of the patients with muscleinvasive TCCU relapse after radical surgery, the majority of them with distant metastases. At the time of the diagnosis about $15 \%$ of patients have advanced disease [4]. Survival for untreated metastatic disease is no longer than six months [5]. The treatment of advanced stages of the disease is based on chemotherapy. Cisplatin-based regimens (Gemcitabine + Cisplatin: GC or Cisplatin + Methotrexate + Doxorubicin + Vinblastine: MVAC) are the cornerstone of first line treatment with a median survival of 13-15 months [6-7]. GC is generally preferred having a better toxicity profile [8]. GC and MVAC are also the standard of care in neoadjuvant/adjuvant setting. Prognosis is dismal at the time of progression after first line chemotherapy or recurrence after neoadjuvant/ adjuvant treatment. When performance status is adequate and relapse occurs later than 12 months after neoadjuvant/ adjuvant therapy, change of platinum based regimen could be considered [9]. Selected patients could be eligible to receive Paclitaxel plus Gemcitabine and Cisplatin [10]. In case of patients unfit for Cisplatin because of a poor performance status (up to $50 \%$ of patients) or impaired renal function, other options - e.g. alternative platinum agents (Oxaliplatin or Carboplatin) or the combination of Paclitaxel and Gemcitabine - have been proposed, although less effective [11-13]. The association with split dose Cisplatin and Gemcitabine could also be considered when the standard dose of Cisplatin cannot 
be administered [14]. Limited treatment options are available after an early relapse following platinum based neoadjuvant/adjuvant chemotherapy or after palliative first-line chemotherapy. The activity of agents, such as taxanes [15] and Pemetrexed [16], has been reported despite not being tested in randomized phase III trials.

Vinflunine is a microtubule inhibitor [17] approved by the European Medicine Agency (EMA) for use in TCCU (2009). Furthermore, it is recommended in ESMO guidelines as a second-line therapy for advanced bladder cancer [18] after first line chemotherapy for advanced disease or at time of recurrence after neoadjuvant/adjuvant treatment.

In the phase III trial [19, 20], Vinflunine was administered at a dose of $320 \mathrm{mg} / \mathrm{m}^{2}$ every 3 weeks for patients with performance status (PS) ECOG 0 and at a dose of $280 \mathrm{mg} / \mathrm{m}^{2}$ every 3 weeks for patients with PS ECOG 0 and a previous pelvic radiation or with PS ECOG 1. Median overall survival was 6.9 months for Vinflunine plus best supportive care versus 4.3 months for best supportive care solely. ORR was $8.6 \%$ for Vinflunine vs $0 \%$ for BSC, disease control rate $41.1 \%$ vs $24.8 \%$, median PFS 3 vs 1.5 months, respectively.

An overall survival of 7-10 months was reported in other studies on efficacy and tolerability of Vinflunine conducted in Spain [21], Germany [22], France [23] and Italy [24].

In the phase III trial, half of the patients experienced grade 3-4 neutropenia. Other relevant grade 3-4 adverse events were: fatigue in $19.3 \%$ of the patients, constipation $16.1 \%$, anemia $19.1 \%$ [19].

Despite being the only cytotoxic agent tested as a second line therapy in TCCU in phase III trials, Vinflunine is not largely employed in clinical practice due to a high incidence of grade 3-4 toxicity.

In order to evaluate the effectiveness and higher tolerability of the dose of $280 \mathrm{mg} / \mathrm{m}^{2}$ every 3 weeks associated with primary prophylaxis for neutropenia and constipation, we conducted this "real life" study including a group of patients with advanced urothelial carcinoma treated with this dose of Vinflunine in a single institution.

\section{RESULTS}

The study included 28 patients with advanced metastatic TCCU treated with Vinflunine between January 2014 and December 2016. Patient characteristics are summarized in Table 1. Vinflunine was administered after first line platinum + Gemcitabine for advanced disease in 15 patients, whereas it was employed at the time of recurrence after neoadjuvant/adjuvant platinum + Gemcitabine in 13 patients.

A total of 143 cycles were administered. The dose was reduced to $250 \mathrm{mg} / \mathrm{m}^{2}$ in 2 patients because of grade IV neutropenia. Overall dose intensity was $93.5 \%$.

Toxicity is reported in Table 2. Grade IIIIV neutropenia occurred in three patients (10.7\%) despite granocyte-colony stimulating factors (G-CSF) prophylaxis. No neutropenic fever was reported. Grade III-IV anemia and Grade III thrombocytopenia were observed in $3(10.8 \%)$ and 2 patients $(7.2 \%)$, respectively. Four patients $(14.2 \%)$ reported grade I-II constipation. Neither grade III-IV constipation nor other grade III-IV adverse events were observed. No patients discontinued treatment because of toxicity.

Overall survival was 8.5 months for the entire population (Figure 1), 8.8 months for patients treated with neoadjuvant/adjuvant chemotherapy and 6.7 months for patients previously treated with a first line chemotherapy (Figure 2) $[p=0.27$, HR 0.65 (95-CI 0.26-1.20)].

PFS for all patients was 4.33 months (Figure 3 ). PFS was 4.9 months and 2.5 months for patients who received neoadjuvant/adjuvant platinum + Gemcitabine and first

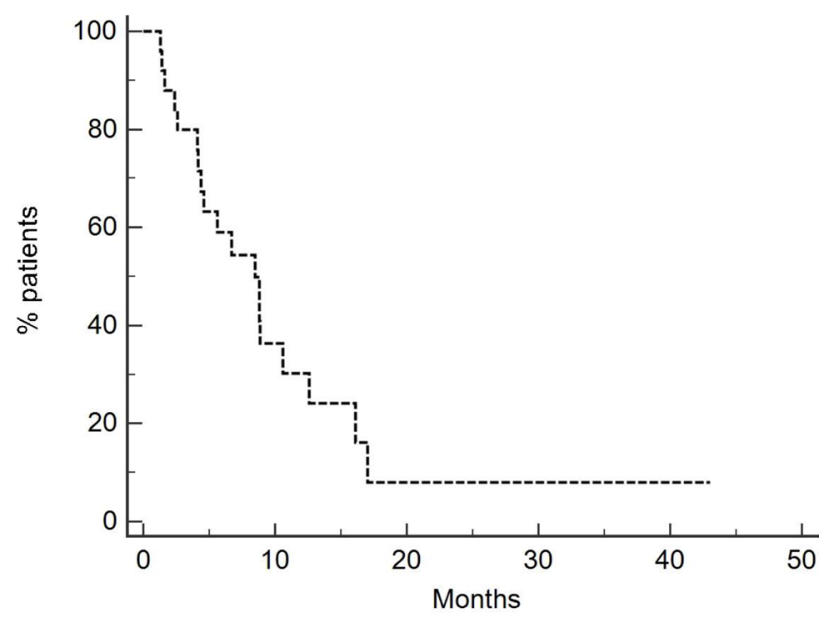

Figure 1: Overall survival of entire population (8.5 months). Twenty-eight patients were treated with Vinflunine at a dose of 280 $\mathrm{mg} / \mathrm{m}^{2}$. 


\section{Table 1: Patients' characteristics}

\begin{tabular}{ll}
\hline Patients & 28 \\
Median age & 64.4 years \\
M/F & $23 / 5$ \\
PS (ECOG) & 14 \\
0 & 14 \\
1 & \\
Platinum/Gem & 10 \\
Neoadjuvant & 3 \\
Adjuvant & 15 \\
Metastatic & 9.7 months \\
Median time from Neoadj/adj to relapse & \\
Prior chemotherapy & 20 \\
Cisplatin + Gemcitabine & 8 \\
Carboplatin + Gemcitabine & \\
Site of recurrence & 24 \\
Lymph-nodes & 9 \\
Lung & 15 \\
Bone & 3 \\
Liver & 1 \\
Other & \\
Subsequent therapies & 22 \\
None & 6 \\
Paclitaxel & \\
\hline & \\
\hline
\end{tabular}

Table 2: Toxicity

Grade I/II n (\%) $\quad$ Grade III n. (\%) $\quad$ Grade IV n (\%)

Haematological

Neutropenia

$5(17.8)$

Neutropenic fever

$-$

$9(32.2)$

$3(10.7)$

Thrombocitopenia

Non haematoligical

Nausea

Dysgeusia

Constipation

$5(17.8)$
$3(10.8)$

$-$

$-$

$2(7.1)$

$2(7.2)$

$1(3.6)$

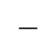

than 8 cycles of therapy. The median response duration was 10.6 months.

\section{DISCUSSION}

Effective agents for second line treatment of advanced TCCU are limited. Drugs commonly used in this setting could yield poor benefits. Due to the short 
survival, an acceptable quality of life should be achieved. Chemotherapy adverse events and frequent hospital admissions could negatively influence patients' wellbeing.

Vinflunine is the only agent approved in Europe as second line therapy in advanced TCCU. In the phase III trial, survival advantages (6.9 months versus 4.3 months for BSC) were counterbalanced by a remarkable incidence of adverse events. In particular, $50 \%$ of the patients experienced grade III-IV neutropenia, 13.1\% grade III-
IV anemia, 16.1\% grade III-IV constipation, 19.2\% grade III-IV fatigue and $51.2 \%$ thrombocytopenia. The toxicity of Vinflunine limited its use, in addition to the restricted advantage on survival.

There is a lack of alternative drugs in this setting. In our study, we tested if the reduction of the dose associated with the use of prophylactic G-CSF and laxatives could allow effective results compared to a higher dose with a better toxicity profile. Indeed, we analyzed patients treated

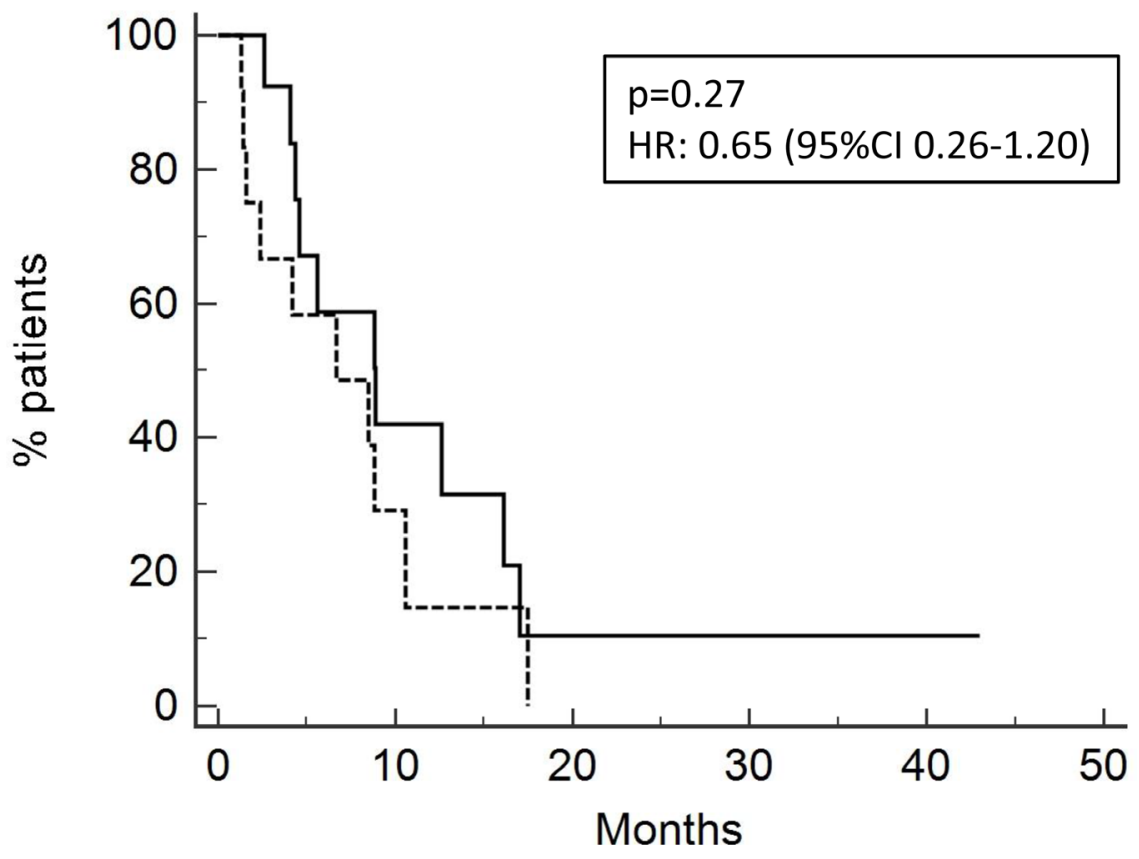

Figure 2: Overall survival of patients relapsed after neoadjuvant/adjuvant treatment (13 pts; OS 8.8 months, solid line) or after chemotherapy for metastatic disease (15 pts; OS 6.7 months, dotted line).

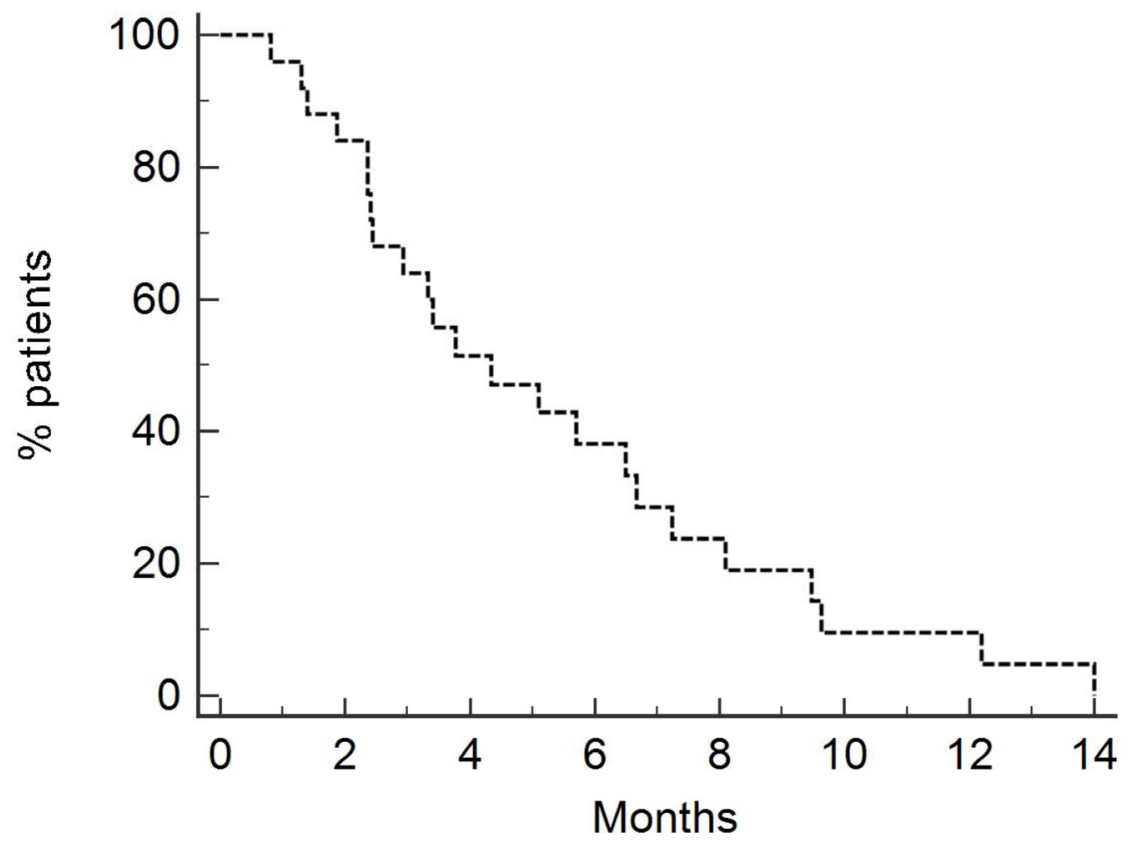

Figure 3: Progression-free survival of entire population (4.33 months). Twenty-eight patients were treated with Vinflunine at a dose of $280 \mathrm{mg} / \mathrm{m}^{2}$. 
Table 3: Response rate

\begin{tabular}{lc}
\hline & n. $(\%)$ \\
\hline Complete response & $1(3.6)$ \\
Partial response & $6(21.4)$ \\
Stable disease & $9(32.2)$ \\
Disease control & $16(57.2)$ \\
Progression & $12(42.8)$ \\
\hline
\end{tabular}

with the dose of $280 \mathrm{mg} / \mathrm{m}^{2}$ every 3 weeks after the failure of a previous platinum + Gemcitabine combination.

Overall survival observed in our study was 8.5 months, PFS 4.3 months, RR $25 \%$, disease control rate $57.2 \%$. These results are similar to those reported in the phase III trial and in other real life studies.

The remarkable duration of response (10.6 months) was obtained through the maintenance of dose intensity, to which the lower incidence of adverse events has contributed. The retrospective nature of the study could have influenced this result. The selection of patients with a high probability of prolonged response could be very useful in clinical practice. Unfortunately, in our study the identification of clinical predictive factors was not possible because of the limited number of patients.

The dose of $280 \mathrm{mg} / \mathrm{m}^{2}$, G-CSF as primary prophylaxis for neutropenia and laxative agents allow the reduction of the most common Vinfluninerelated adverse events. As a matter of fact, grade IIIIV neutropenia was $10.7 \%$, instead of the rate of $50 \%$ reported in the phase III trial. Grade III-IV anemia and all grade thrombocytopenia occurred in $10.7 \%$ and $17.9 \%$, respectively, compared to $19.1 \%$ and $51.2 \%$ reported by Bellmunt [19].
Concerning non haematological toxicity, in our population only grade I-II constipation and fatigue were observed (14.2\% and $17.8 \%$, respectively) whereas Bellmunt [19] described grade III-IV fatigue in $19.3 \%$ and grade III-IV constipation in $16.1 \%$.

These data confirm a good tolerability of this drug and show a milder toxicity with the dose tested in our study. Prospective clinical trials should be helpful to confirm our observations. They could also represent a source for further pharmacokinetics information and for clinical and pathological predictive factors.

Despite being retrospective and including a limited number of patients, this study underlines that Vinflunine at a dose of $280 \mathrm{mg} / \mathrm{m}^{2}$ is effective and has a favorable toxicity profile. Vinflunine as administered in our study could be considered for the second line treatment of advanced TCCU also in the next future, when immunological checkpoint inhibitors [25] might be available in clinical practice.

\section{MATERIALS AND METHODS}

Patients with advanced metastatic TCCU, PS (ECOG) 0-1, relapsed within 12 months after neoadjuvant/

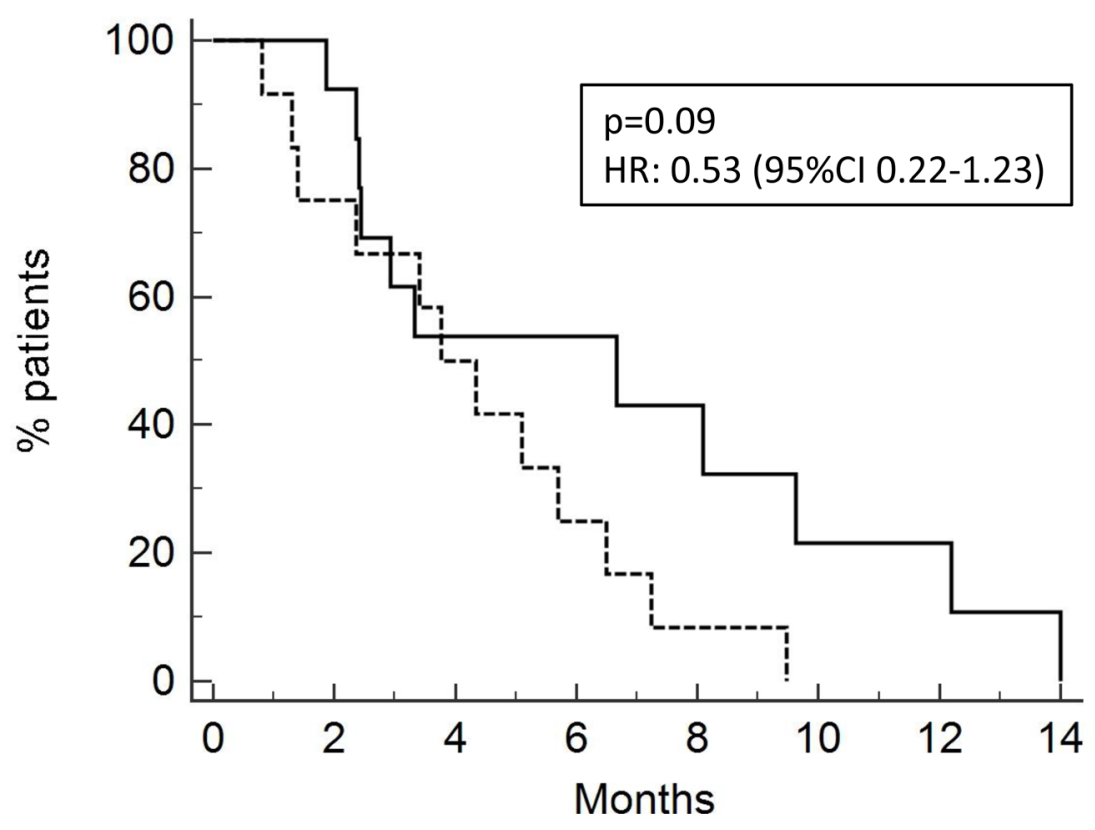

Figure 4: Progression-free survival of patients after neoadjuvant/adjuvant treatment (13 pts ; PFS 4.9 months, solid line) or after chemotherapy for metastatic disease (15 pts; 2.5 months, dotted line). 
adjuvant platinum-based chemotherapy or progressed after a first line platinum-based treatment were included in this retrospective analysis. The dose of Vinflunine administered was $280 \mathrm{mg} / \mathrm{m}^{2}$ intravenously every 3 weeks for the entire population. Emollient laxatives were used for primary prophylaxis of constipation. Paraffin oil was prescribed fasting at the dose of $15 \mathrm{ml}$ twice a day for 7 days after chemotherapy administration. The timing of administration was chosen based on the nadir of constipation, that occurs 3-5 days after Vinflunine administration. Granocyte-colony stimulating factors (G-CSF) were given as primary prophylaxis of neutropenia: Lenograstim $34 \mathrm{MU}$ was administered for 6 days starting 24 hours after Vinflunine. We collected all demographic data related to patients: gender, age, previous treatments (in neoadjuvant/adjuvant or advanced setting), site of recurrence.

The primary outcomes were overall survival (OS) and toxicity; other outcomes were progression-free survival (PFS) and response rate (RR).

OS was calculated from the first day of cycle 1 to death and PFS from the first day of cycle 1 to progression or death. The Kaplan and Meier method was used; the comparison of survival between patients' subgroups was obtained by the log-rank test. A Cox-proportional hazard model with $95 \%$ confidence interval (CI) was used to calculate the hazard ratios. All $p$-values were considered significant at the 5\% level. Responses were evaluated trough RECIST criteria version 1.1.

Toxicity was reported using Common Terminology Criteria for Adverse Events (CTCAE) version 4. Data on tolerability were collected considering all the adverse events occurred throughout the treatment period. Clinical evaluations were performed every 3 weeks before Vinflunine administration. Visits were also performed monthly after the end of Vinflunine.

Our study was approved by local Ethic Committees and conducted according to the Helsinki Declaration. All the patients released a written informed consent.

\section{CONFLICTS OF INTEREST}

None.

\section{REFERENCES}

1. Pasin E, Josephson DY, Mitra AP, Cote RJ, Stein JP. Superficial bladder cancer: an update on etiology, molecular development, classification, and natural history. Rev Urol. 2008; 10:31-43.

2. Amin NB, McKenney JK, Paner GP, Hansel DE, Grignon DJ, Montironi R, Lin O, Jorda M, Jenkins LC, Soloway M, Epstein JI, Reuter VE. ICUD-EAU international consultation on bladder cancer 2012: pathology. Eur Urol 2013; 63:16-35.
3. International Agency for Research on Cancer. Globocan 2012. Estimated cancer incidence, mortality and prevalence worldwide in 2012. http://globocan.iarc.fr/Default.aspx.

4. Stein JP, Lieskovsky G, Cote R, Ghoshen S, Feng AC, Boyd S, Skinner E, Bochner B, Thangathurai D, Mikhail M, Raghavan D, Skinner DG. Radical Cystectomy in the treatment of invasive bladder cancer: long-term results in 1,054 patients. J Clin Oncol. 2001; 19:666-675.

5. Sternberg CN, Vogelzang NJ. Gemcitabine, paclitaxel, pemetrexed and other newer agents in urothelial and kidney cancers. Crit Rev Oncol Hematol. 2003;46 Suppl:S105S115.

6. Bellmunt J, Petrylak DP. New therapeutic challenges in advanced bladder cancer. Semin Oncol. 2012; 39:598-607.

7. Von der Maase H, Sengelov L, Roberts JT, Ricci S, Dogliotti L, Oliver T, Moore MJ, Zimmermann A, Arning M. Longterm survival results of a randomized trial comparing gemcitabine plus cisplatin, with methotrexate, vinblastine, doxorubicin, plus cisplatin in patients with bladder cancer. J Clin Oncol. 2005; 23:4602-4608.

8. Von der Maase H, Hansen SW, Roberts JT, Dogliotti L, Oliver T, Moore MJ, Bodrogi I, Albers P, Knuth A, Lippert CM, Kerbrat P, Sanchez Rovira P, Wersall P, et al. Gemcitabine and cisplatin versus methotrexate, vinblastine, doxorubicin, and cisplatin in advanced or metastatic bladder cancer: Results of a large, randomized, multinational, multicenter, phase III study. J Clin Oncol. 2000; 18:30683077 .

9. Necchi A, Pond GR, Giannatempo P, Di Lorenzo G, Eig1 BJ, Locke J, Pal SK, Agarwal N, Poole A, Vaishampayan UN, Niegisch G, Hussain SA, Singh P, et al. Cisplatinbased first-line therapy for advanced urothelial carcinoma after previous perioperative cisplatin-based therapy. Clin Genitourin Cancer. 2015; 13:178-184.

10. Bellmunt J, von der Maase H, Mead GM, Skoneczna I, De Santis M, Daugaard G, Boehle A, Chevreau C, Paz-Ares L, Laufman LR, Winquist E, Raghavan D, Marreaud S, et al. Randomized phase III study comparing paclitaxel/cisplatin/ gemcitabine and gemcitabine/cisplatin in patients with locally advanced or metastatic urothelial cancer without prior systemic therapy: EORTC Intergroup Study 30987. J Clin Oncol. 2012; 30:1107-1113.

11. Carles J, Esteban E, Climent M, Font A, GonzalezLarriba JL, Berrocal A, Garcia-Ribas I, Marfa X, Fabregat X, Albanell J, Bellmunt J; Spanish Oncology Genito Urinary Group Study Group. Gemcitabine and oxaliplatin combination A multicenter phase II trial in unfit patients with locally advanced or metastatic urothelial cancer. Ann Oncol. 2007; 18:1359-1362.

12. De Santis M, Bellmunt J, Mead G, Kerst JM, Leahy M, Maroto P, Skoneczna I, Marreaud S, de Wit R, Sylvester R. Randomized phase II/III trial assessing gemcitabine/ carboplatin and methotrexate/carboplatin/vinblastine in patients with advanced urothelial cancer 'unfit' for 
cisplatin-based chemotherapy: Phase II -results of EORTC study 30986. J Clin Oncol. 2009; 27:5634-5639.

13. Calabrò F, Lorusso V, Rosati G, Manzione L, Frassineti L, Sava T, Di Paula ED, Alonso S, Sternberg CN. Gemcitabine and paclitaxel every 2 weeks in patients with previously untreated urothelial carcinoma. Cancer. 2009; 115:2652-2659.

14. Hussain SA, Stocken DD, Riley P, Palmer DH, Peake DR, Geh JI, Spooner D, James ND. A phase I/II study of gemcitabine and fractionated cisplatin in an outpatient setting using a 21-day schedule in patients with advanced and metastatic bladder cancer. Br J Cancer. 2004; 91:844-849.

15. Sideris S, Aoun F, Zanaty M, Martinez NC, Latifyan S, Awada A, Gil T. Efficacy of weekly paclitaxel treatment as a single agent chemotherapy following first-line cisplatin treatment in urothelial bladder cancer. Mol Clin Oncol 2016; 4:1063-1067.

16. Bambury RM, Benjamin DJ, Chaim JL, Zabor EC, Sullivan J, Garcia-Grossman IR, Regazzi AM, Ostrovnaya I, Apollo A, Xiao H, Voss MH, Iyer G, Bajorin DF, et al. The safety and efficacy of single-agent pemetrexed in platinumresistant advanced urothelial carcinoma: A large singleinstitution experience. Oncologist. 2015; 20:508-515.

17. Bennouna J, Delord JP, Campone M, Nguyen L. Vinflunine: A new microtubule inhibitor agent. Clin Cancer Res. 2008; 14:1625-1632.

18. Bellmunt J, Orsola A, Maldonado X, Kataja V, ESMO Guidelines Working Group. Bladder cancer: ESMO Practice Guidelines for diagnosis, treatment and follow-up. Ann Oncol. 2010; 21(Suppl 5):v134-v136.

19. Bellmunt J, Théodore C, Demkov T, Komyakov B, Sengelov L, Daugaard G, Caty A, Carles J, Jagiello-Gruszfeld A, Karyakin O, Delgado FM, Hurteloup P, Winquist E, et al. Phase III trial of vinflunine plus best supportive care compared with best supportive care alone after a platinum- containing regimen in patients with advanced transitional cell carcinoma of the urothelial tract. J Clin Oncol. 2009; 27:4454-4461.

20. Bellmunt J, Fougeray R, Rosenberg JE, von der Maase H, Schutz FA, Salhi Y, Culine S, Choueiri TK. Long-term survival results of a randomized phase III trial of vinflunine plus best supportive care versus best supportive care alone in advanced urothelial carcinoma patients after failure of platinum-based chemotherapy. Ann Oncol. 2013; 24:1466-1472.

21. Castellano D, Puente J, de Velasco G, Chirivella I, LópezCriado P, Mohedano N, Fernández O, García-Carbonero I, González MB, Grande E. Safety and effectiveness of vinflunine in patients with metastatic transitional cell carcinoma of the urothelial tract after failure of one platinum-based systemic therapy in clinical practice. BMC Cancer. 2014; 14:779.

22. Hegele A, De Geeter P, Goebell P, Matz U, De Schultz W, Retz M. Vinflunine in routine practice for the treatment of advanced or metastatic urothelial cell carcinoma in Germany. Eur J Cancer. 2013; 49:669-669

23. Medioni J, Guillot A, Spaeth D, Di Palma M, Theodore C. Historical data in real life from patients treated by vinflunine for an advanced or metastatic urothelial carcinoma: Results of the CURVE study. Eur J Cancer. 2013; 49:S646-S647.

24. Facchini G, Della Pepa C, Cavaliere C, Cecere SC, Di Napoli M, D’Aniello C, Crispo A, Iovane G, Maiolino P, Tramontano T, Piscitelli R, Pisconti S, Montella M, et al. From Clinical Trials to the Front Line: Vinflunine for Treatment of Urothelial Cell Carcinoma at the National Cancer Institute of Naples. Front Pharmacol 2016; 7:1-7.

25. Bellmunt J, de Wit R, Vaughn DJ, Fradet Y, Lee JL, Fong L, Vogelzang NJ, Climent MA, Petrylak DP, Choueiri TK, Necchi A, Gerritsen W, Gurney H, et al, KEYNOTE-045 Investigators. Pembrolizumab as Second-Line Therapy for Advanced Urothelial Carcinoma. N Engl J Med. 2017; 11:1015-1026. 